\title{
ERP Business Process Attributes to Create Competitive Advantage
}

\author{
Izzeideen Ata Alomari, Ziad Jalal Aldammagh \\ Faculty of Administrative and Financial Sciences, Gaza University, Gaza, Palestine
}

Email address:

izzeideenalomari@gmail.com (I. A. Alomari)

\section{To cite this article:}

Izzeideen Ata Alomari, Ziad Jalal Aldammagh. ERP Business Process Attributes to Create Competitive Advantage. International Journal of Business and Economics Research. Vol. 10, No. 1, 2021, pp. 40-49. doi: 10.11648/j.ijber.20211001.16

Received: December 10, 2020; Accepted: January 4, 2021; Published: January 25, 2021

\begin{abstract}
During the industry 4.0 revolutions and business intelligence era, in which automation and data exchange in manufacturing technologies becomes a prerequisite. Therefore, companies aspiring for achieving competitive advantage need to be updated with the latest technologies. Enterprise Resource Planning (ERP) systems are among the most up-to-date integrated information systems which play particularly important role in overseeing and coordinating all the activities, information and functions and information of a business from common database. Despite the fact that previous studies indicate a lack of understanding of the relationship between ERP systems and competitive advantage using each of ERP business processes attributes (i.e. integration, standardization, routinaziation and centralization) need to be investigated. Based on the 114 functional answers, the data was examined utilizing the following approach: structural equation modeling (SEM) via the software: partial least square (PLS). The results offer empirical evidence on the importance of every ERP attribute in determining firm's competitive. Evidently, there is a positive association between such variables and the competitive benefit. Such findings present an insight on the association between ERP attributes and the competitive advantage of an enterprise, which could be an input for businesses so as to encounter the industrial digitalization and the era of business intelligence.
\end{abstract}

Keywords: Resource Planning Systems, Integration, Centralization, Routinization, Standardization

\section{Introduction}

Peripheral to technology development, business competition has increased hence expanding the scope of managerial accounting from archival value to more real time reporting [1]. To date, big data and business analytics which involve large or unstructured data sets play crucial role in every aspect of major companies' decision making, strategic analysis, and forecasting allowing millions of data elements to be created, purchased, extracted, collected, processed, and analyzed from external and/or internal sources to maintain a competitive edge [2]. Based on this challenge, an effective manufacturing strategy must take into account the competitive advantage of the companies over their competitors [3]. In practice competitive advantage is usually reflected in its superiority in production and performance outcome [4, 5]. Similarly, Chenhall [53] viewed the achievement of competitive advantage as a strategic outcome, an indicator of competitive strategy. Few researchers $[4,6]$ also presented the same perspective arguing competitive advantage as a performance outcome. Hence, as these large and unstructured datasets would not be easily analyzed on database management systems and software programs [7] also, high quality data is needed to be complete, precise, valid, accurate, relevant, consistent, and timely [8] companies resorted to implement Enterprise Resource Planning (ERP) systems. The ERP systems are integrated information systems within an organization playing important role in overseeing and coordinating all the functions, information, and resources of a business from common stores of data hence improving the capability of management accountants to fulfill the above-mentioned roles by providing management with access to relevant and real-time operational data in the support of decision making and management control rendering increased organization's efficiency $[9,10]$. In addition, Enterprise Resource Planning (ERP) systems have been proven to be the solution for the information needs of many businesses, although Davenport [46] described that ERP implementation can be challenging, time-consuming, expensive, and can place tremendous stress on corporate time and resources. Due to these barriers, almost 66 to 70 per cent 
of ERP implementation projects were unsuccessful in achieving the implementation objectives in some way [11]. Studies have shown that ERP implementation failure is common even in projects with the most favorable conditions [12]. The discussion on the issue remains inconclusive.

Previous studies in ERP systems in the area of business studies couldn't assess and measure ERP systems in proper assessment, by examining its business process which consists of - integration, centralization, routinization and standardization [13-15]. Studies were focusing on system outcome using one attribute which is integration, over its main four attribute.

As ERP system stands as a long-term strategic investment and the lengthy implementation process poses influence on the whole organization, it is imperative that competitive advantage of the firm is sustainable over the whole adoption periods which may take several years. This study would contribute to the ERP system literature in two main aspects. Primarily, this study would increase the breadth and depth of ERP systems [16-19, 9] and offer evidence of how competitive advantage could be achieved due to the effects of ERP systems through each of business process attributes for a proper ERP assessment $[15,13]$.

\section{Literature Review}

The notion of ERP is that it achieves logistical notions from materials requirements planning (MRP) and manufacturing resource planning (MRP II). As an alternative to utilizing many systems in managing the business of a firm, ERP functions as a means for a firm to rationalize into one combined system from what primarily were conventionally discrete operations. This allows the flow of information from operation to operation shared through a prevalent ERP system, thereby generating more processes with straightforward companywide communication, higher quality reporting and higher productivity. Al-Mashari et al. [43] stated that the basic architecture of an ERP system generates a unified interface, an application and a database for whole firm. ERP facilitates the transactions of business in companies and used to create massive advantage, it is the software application that makes it potential for the business to well accomplish their operations [21].

Through multiple case studies, Sanchez and Spraakman [15] try to enhance the understanding of ERP implementation and its impact on the accounting and control of management. Results revealed that the volume of data entry carried out by the accountants of management had been decreased due to the automation and standardization of transaction processing. Standardized performance measures which extended to more products and units leading to an increase production rate as well as accuracy. Furthermore, there were more effective and efficient management accounting strategies and less involvement with data entry making it possible for the accountants of management to conduct more analyses and extensive non-financial information. In short, these four attributes were the benefits of ERP (a) more precise and appropriate information (b) increased the availability of information across all products as well as units (c) and decreased the amount of data entry carried out by the accountants of management. The study emphasized the main issue to support the influence of ERP on the accounting of management and also its effect in understanding the different levels of ERP systems in terms of physical, transactional and informational.). Thus, the process of business could be viewed as flows through various functions in a firm [23, 14]. In addition, according to Alomari et al. [44], the process of business is a limited group of unified work practices that provides output of bigger value than the inputs through one or more transformations. As compared to Sanchez who classified different levels of ERP systems in terms of physical, transactional and informational. Alomari et al. [44] classified transformations as: informational, physical, transactional and locational. Accordingly, business process referred to the "input" and the "output" represents the transformations flows among activities and usually consist of information.

Organizations which switch focused systems of information to incorporated company systems like the systems of ERP can avoid depending on manually linking useful systems of information that work by copying information from one system and reenter it into the next system which would not be feasible provided the difficulty of dealing with the data across whole process of business. Enterprise systems support this entire process rather than portions of it, encapsulates the interdependence of functions, departments, people, roles, and tasks, and offer customer with a service or product in a comprehensive manner [24, 14]. While other researchers discuss ERP system from different perspectives, Scapens and Jayazeri [13] proposed ERP based on a user perspective. It was notable that the research by this group actually underlined the characteristics of integration. Apparently subsequent studies by Sanchez 2012 did accept this conceptualization. Based on a longitudinal case study conducted in the European department of a great United States multinational, Scapens and Jazayeri [13] established four attributes which are deemed necessary in facilitating changes in organization through ERP implementation. Recently, Alomari et al. [29] maintained that the single-instance ERP rolling out was not only about the standardization of technology, but also consisted of the integration of data as well as standardization of business process. Consequently, the current study will look into ERP systems using business process attributes following Scapens and Jazayeri [13] and Sanchez and Spraakman [15].

\subsection{Integration Business Process}

Integration is considered to be one of the relevant ERP attributes [25]. Nevertheless, IT literature notion of integration is frequently deliberated, the precise gist of the term continued to be blurred [47]. The business process of information system could be incorporated with diverse magnitudes. Booth et al. [45] recognize three aspects of integration, namely, integration of information, software/hard integration and integration of data. The integration of data 
denotes the above-mentioned attribute of IIS which data are kept and preserved in one appropriate area only, while hardware/software integration denotes the network connectively in the processors that can interconnect mutually. Lastly, information integration refers to the smoothness information can be exchanged among all sections. The software/hardware integration and data integration denote practical characteristic of integration, whereas the integration of information denotes business characteristics. Booth et al [45] underscore the fact that systems might not be greatly incorporated without examining the effect of technical aspect and business aspect combined. In the meantime, Chapman and Kihn [42] measured integration system with regard to two objects which are fully-incorporated system information and information in reports generated by IS (e.g. ERP) and that comprise both non-financial and financial information.

Contrarily, Berente et al. [22] used a case study in five administrations to theorize integration slightly dissimilar to other researches. The research defines integration process of business with reference to accessibility of information to be utilized in business process /decision between undertakings. They precisely recognize business integration process via these principles:

1. Accessibility indicates the capability of accessing information inside the process from every needed point.

2. Timeliness indicates the flow of the information conducted from one mission to another instantaneously.

3. Transparency indicates the simplicity which enables information transformed from one task to another to be perceived.

4. Granularity indicates the fact that all information swapped in the process should be delivered with detail.

The model that discusses the component of integration implemented by Berete et al. [22] is like the integration element adopted in Scapens and Jazayeri's [13] model. This study will draw on Berente et al.'s perception. Business process integration is to be reinforced by standardization, centralization and routinization ERP business process for improved ERP valuation and that will be deliberated in the next section.

\subsection{Standardization Business Process}

Standardization indicates ERP system employed in businesses' divisions or sections, made in firms, and forced from the company's HQs [13]. Companies try to systematize processes for numerous significant motives. Inside a firm, standardization can simplify communications regarding business operations, assist easy transfer through process restrictions, and enable relative performance measures [46]. Several scholars think that standardized processes of business are better to outsource and that there exist experimental clues which indicates the fact that the standardization of business process decreases the business process risks [15, 61, 26].

Many studies mentioned frequently standardization of data [13], yet, the concept is still vague. Previously, Granlund and Malmi [26] stated that standardization provides easier and more rapid access to (standardized) functional data. It is contended that the most significant advantages of the standardization of ERP is that it improved computing power and general standardization direct to more exact and welltimed information [15]. The standardized processing of transaction has developed the accessibility of information from products and a unit initially lacking information, and guaranteed a constancy of information all the way through every part and product the transaction processing standardization has decreased the quantity of the entry of data prepared by the accountants of management. Additionally, Caglio [48] stated that a progressive level of standardization of accounting practices and activities headed to the requirement for inter-functional cooperation and integration. Therefore, it is in agreement with this, the current study proposes the need to detect both standardization and integration of ERP characteristics. Consequently, the scholarships discussed before emphasized that ERP standardization has constructive effect on business process. There is an encouraging influence of business process Standardization on business and organization products [61].

Numerous academics $[62,61]$ focused on the standardization of business process. Particularly, standardized processes would show enhanced performance. Furthermore, the standardization of business process reduces the risks of outsourcing of business process [61]. Likewise, based on the previous studies related to supply chain and production, business process standardization is intended to develop functional performance and lessen costs by reducing process inaccuracies and assisting communications [62, 60]. Consequently, it appears to be stimulating to advance the systems ERP of standardization of business process for the evaluation of enhanced ERP systems to well accomplish effect of the systems of ERP on competitive advantage.

Caglio [48] accentuated the fact that integration has to follow standardization. In the meantime, Scapens and Jazayeri defined standardization and integration as ERP attributes that required better-quality understanding of the systems of ERP.

\subsection{Routinization Business Process}

Routinization indicates the assumed routine accounting and further information processing actions by ERP system [13], Because of ERP systems are exceedingly adaptable, configurable, and flexible and having an incorporated design, a rise in routinization of ERP systems help business processes inside an institute to be widely and customarily reconfigured for substitute resources while simultaneously lessening the cost and period of switching these resources [21]. For the meantime, Literature on routinization similarly proposes that knowledge sharing allowed by improved routinization of ERP systems might cause reduced administrative liveliness by supporting situations held by directors that are from what has succeeded previously and achieve ERP effective implementation [21]. Moreover, routinization, as a concept, was part of Scapens and Jazayeri [13] model. Nonetheless, few studies have empirically witnessed $\backslash$ studied these characteristics. Therefore, routinization as one of ERP systems 
attributes needs to be deliberated so as to define the system for comprehending the advantages of the systems completely.

Hage and Aiken [49] examined the association between organizational technologies, specially the amount of routine in work. They found that organization with repetitive tasks highlights objectives of competence and value of customer services. They inspected the routines by means of numerous questions. The first question reads: "Would you describe your work as being very routine, somewhat routine, somewhat non- routine, or very nonroutine?" This question, together with many others created by Hall [50] encumbered together in a factor analysis of different characteristics of organizational conduct and seems to illustrate a distinct and different measurement demonstrating work's routineness. Questions used by Hall:

1. There exits something new to carry out daily.

2. One thing that individuals prefer around here is the work variety.

3. Individuals here carry out the same job in the same manner daily.

4. The majority of jobs have something new taking place on a daily basis.

Consequently, this research provides the routinization measurements supported by other attributes that are provided for accomplishing the best ERP assessment.

\subsection{Centralization Business Process}

In deliberating on centralization, Scapens and Jazayeri [13] pointed out it is significant to take into consideration both the centralization of other support activities as well as the centralization of systems control and design. Quattrone and Hopper [63] examined the impact of employing a system of ERP on the control of management in two companies of international establishments. It emphasized the effect on the process of business is also ascribed to the data centralization structure. It was carried out by concept-packaging standardization and centralization methods when obtaining new companies, and applying control systems as well as IT amid them. Sanchez et al. [15] contended that centralization guides to apt and decrease data access through automation. Accordingly, building on the degree of centralization and other ERP systems characteristic centralization routinization, standardization and integration of business process systems would be an imperative matter for the studies on the systems of ERP.

Lastly, the business process centralization could be carried out by utilizing either decentralized or centralized business process introduced in [51] and then the centralization level could be examined.

\section{Hypotheses Development}

Investment in ERP systems in companies comes with the expectation of obtaining the aims in increasing some assets and abilities along with technical and managerial competencies in order for the firm to develop opportunities and values for differential long term major benefits [27]. The implementation of ERP system would directly bring operational advantages through innovation capacity building and stimulation involving the technology that subsequently provide the long-term benefits opportunities and lead to the creation of value [27] which in the long run lead to competitive advantage [28, 29]. Previous studies put emphasis on the significance of creating integration which leads to improvement of firm's competitive advantage. Alomari et al. [29] showed that ERP integration system leads to improvement of competitive advantage. Similarly, Mirzaee \& Ghaffari [52] argued that implementing effective ERP systems (standardized, centralized, routinized and integrated) can accelerate the speed of information exchange among the personnel and the improvement of their capabilities, the results gained in this study revealed that ERP systems play a positive significant role in competitive advantage.

Drawing from the existing literature, this study argue that in assimilation phase leads to the following hypothesis which is, the integration of business process will be positively related with competitive advantage as following:

$H 1$ : Integration is positively related to competitive advantage. ERP system is standardized to enable firms to better manage their knowledge through and create effective knowledge manner that helps to create competitive advantage [30]. In addition, Caglio [48] observed that a higher degree of standardization of accounting activities and practices led to the need for integration and inter-functional collaboration which will lead to increase effectiveness toward competitive advantage. Previously, studies have been argued that Standardization lead to effective knowledge sharing, and that will lead to the second hypothesis related to ERP system as follow:

$H 2$ : Standardization is positively related to competitive advantage.

Generally, to facilitate the business process, organizations must develop linkages to the source of knowledge that can act as facilitators for knowledge transfer, and mechanisms through which the knowledge can be shared or transferred. Such mechanisms include business process centralization in order to enhance competitive advantage [31]. Moreover, the act of competitive advantage done not come automatically but must be facilitated by involving the centralization of ERP and business process to create competitive advantage [29]. Those will lead the study to propose the third ERP business process hypothesis as follow:

H3: Centralization is positively related to competitive advantage.

The diffusion of ERP usage across organizational business processes and the routinization of activities within these processes referred as ERP assimilation. Following ERP implementation in an organization and its routinized usage as well as its embedment within an organization's work processes and value chain activities, this leads to institutionalization of ERP system [29]. Routinization of business process argued to automate the transactions which lead to timely and shared information [15] which lead to competitive advantage. Based on the argument, it can be hypothesized that: 
H4: Routinization is positively related to competitive advantage.

\section{Research Method}

The sample of the study was chosen with a stratified sampling technique where the sample was randomly extracted from the Federation of Malaysian Manufacturers database. A random sample featured 972 Malaysian manufacturing companies (FMM 2016). Table 3 provides a summary of the sizes and sectors of the investigated institutions.

The current study chose the manufacturing sectors because of certain features including their high level of environmental effect as well as their diversity and complexity in many areas which make them distinctive from other sectors [34, 33]. The surveys were addressed to the COOs of manufacturing firm's directors of randomly selected manufacturing firms. The number of questionnaires sent to each company varied according to the size of the firm and the number of their core business units. A total of 972 survey questionnaires were sent via email in batches over a week from 13 February to 30 March 2016. However, whenever possible the questionnaire was personally delivered to the respondents. To preserve the anonymity of the respondents, the surveys did not require respondents to identify themselves or their company, and were not pre-numbered.

After the one month and half, about 14 responses were received and follow-up with emails reminders for late respondents and to thank those who had already returned their questionnaires. There were companies that had refused to participate in the survey and they were struck off the sample. The main reasons for refusing to take part in the present study were either so busy or because the study was against the policy of the firm. The third mailing was sent out a month after the second reminder. The follow-up consisted of another reminder letter. The data was collected over a four month period from 13 February 2016 to 20 June 2016.

\section{Measurements of Variables}

Established data collection tools were employed as much as possible so as to increase the reliability of the findings. Nevertheless, some of these tools were modified or supplemented to satisfy the study requirements. To measure the study variables, multiple indicators were used through multi-item constructs on seven-point Likert scales. Extensive pilot testing by a small group of managers as well as academics was also used to enhance the content validity of the measures. The utilized questionnaire was pre-tested on a rigorous process of review by five business managers as well as seven academic experts majoring in management accounting, ERP systems. The ultimate measures were subsequently refined and improved.

\subsection{Enterprise Resource Planning Systems}

The ERP system measurements are grounded on an amalgamation of Scapens and Jazayeri [13], SánchezRodríguez and Spaakman [15] and Magal and Word [14] which are comprised of four attributes of business process, namely, centralization, routinization, standardization, and integration of business process. The instrument offered by Berente et al. [22] was employed for the measurement of business process integration, namely, granularity, transparency, accessibility and timeliness; a modification of measurement of Wang and Strong [55] was used to measure transparency; Hsu and Liao [54] was employed for measuring accessibility and Chenhall and Morris [64] was utilized for measuring the timeliness. Respondents were inquired about the extent to which such items describe their organization ERPs where the answers range from a very great extent to not at all. Nine out of 37 items were deleted because of the low factor loadings (refer to Appendix).

\subsection{Measurements of Competitive Business Strategy}

The competitive advantage of a firm was measured utilizing a tool initially proposed by Govindarajan [56]. Based on the activities related to the low cost and differentiation strategies, six items were employed for measuring the extent to which the manager locate their enterprise in relation to those of leading competitors, namely, product features, marketing costs, research and development costs, product selling price, brand image and product quality. The tool has been extensively employed and validated in much accounting research (for instance, $[35,56]$. Chenhall and Langfield-Smith [57] combined much emphasis on accessibility of after-sales services, rapid product changes, production costs, customized product and product availability. Chenhall [65] extended and enhanced this measurement and such an extension was employed in the present study. The participants were asked to rate each of the eleven items which range from "very important" to "not important", showing the degree of significance of the strategic priorities to their organizations. Then, they were required to rate the real performance of those eleven strategic priorities in comparison to their competitors. A likert scale ranges from 1 "well below" and 7 "well above" as compared to the strategic priorities performance of their competitors. Scores of every dimension were measured by multiplying "strategic priorities performance" and the respective "importance" items. A final level of competitive advantage for every organization was identified by taking the mean of all questionnaire items.

\section{Data Analysis- Partial Least Square (PLS)}

The study used SmartPLS- structural equation model (SEM) to analyse the data [9]. The study attained the estimates of partial least squares (PLS) for both the structural model and measurement. The PLS software imposes minimum requirements on the levels of measurement, does not require multivariate standard data, and is suitable for 
small samples [36], and this is so prevalent in the studies related to management accounting [37]. Moreover, the method of PLS is more appropriate for models including complex associations like several relationships, variables, and indicators [34]. Besides, bootstrapping was carried out to identify the significance level of every item [39]. Ylinen and Gullkvist [37] claimed that bootstrapping is proposed for small samples which do not adopt a multivariate regular distribution. A big number of subsamples are provided in the bootstrapping process among which the replacement from the original data sets [38]. Subsequently, every subsample is employed to assess the model. Such an exertion utilized 5000 bootstraps as well as 114 cases from the original sample so as to test the present research hypotheses. The 5000 bootstrapped samples were drawn to approve that the whole parameter of the model has practical sampling distribution and also to achieve its standard error.

\section{Results}

\subsection{Measurement Model: Assessing Psychometric Properties}

Measurement model assessment includes the examination of constructs and items relationships. By using reflective measurement model, the assessment will be including indicator loading, internal consistent reliability, indicator reliability, convergent validity and discriminant validity. The common item loading for the indicator loading as regarding to Chin [58] and Fornell \& Larcker [59] is.708 or higher. Though, it is considered common to have loading of weaker items in research of social science and deleting such items with low loading need to be carried out as caution to impact the constructs' content validity [39]. Moreover, according to Hair et al. [38] it's allowed to remove the items that include outer loading between. 4 and.7, incase such removed items may result in increasing the composite reliability value and average value extracted (AVE). The outer loading has shown in appendix A before item removal.

The result of the PLS algorithm shows that most of the item loading exceeded 0.7 and below 0.85 . Considering the low and over loading of items were removed as shown in appendix A. Eleven items removed due to low loading factor $<0.7$. Also one item was removed due to high Collinearity (based on VIF value) which made composite reliability value more than 0.95 as acceptable levels. According to Hair [38] maximum acceptable of composite reliability is 0.95 and if there are items in the same construct which are highly correlated should be removed to reduce the composite reliability. After removing the low loading items, AVE and composite reliability were reexamined. The findings validate highest convergent validity for the centralization of ERP systems with AVE value.712 and the lowest was routinization of business process with 0.533 which exceeding the minimum AVE value with level of 0.5 (refer to Appendix A). The assessment of cross loading for level of items discriminant validity followed by Fornell-Larcker test as assessment of constructs discriminant validity. Referring to Fornell and Larcker [59] the AVE square root of each construct should be higher than the correlation of latent variables' with any other constructs in the study model. Nevertheless, Hair et al. [38] maintained that if some constructs are found to be higher than the AVE square root, this construct could be eliminated by the researcher as its value is higher than the AVE square root so as to more closely be congruent with the Fornell-Larcker criterion and to enhance the discriminant validity or reliability. However, the researcher should also take into account that the process of removal does not influence the content validity measurement (Refer to Table 1).

Table 1. Discriminant validity - Fornell-Larcker criterion.

\begin{tabular}{llllll}
\hline & C & CM & I & R & S \\
\hline $\mathrm{C}$ & 0.8436 & & & & \\
$\mathrm{CM}$ & 0.6665 & 0.8115 & & & \\
$\mathrm{I}$ & 0.7783 & 0.7393 & 0.8029 & & \\
$\mathrm{R}$ & 0.5446 & 0.5257 & 0.4911 & 0.7302 & \\
$\mathrm{~S}$ & 0.5595 & 0.6082 & 0.5499 & 0.5813 & 0.8395 \\
\hline
\end{tabular}

$\mathrm{C}=$ Centralization; $\mathrm{S}=$ Standardization; $\mathrm{R}=$ Routinization; $\mathrm{I}=$ Integration; $\mathrm{CM}=$ Competitive Advantage.

\subsection{Structural Model}

The next step after assessing the measurement model is supporting the theory and literature of study by the empirical data by the structural modeling of results to determine both the theory and notions are confirmed for the anticipated hypotheses by the empirical results or not. The structural modeling included the assessing of collinearity, the predictive relevance (Q2), path coefficient, size impact of (f2) and (R2) level [39]. For collinearity issues it can be attained by variance inflation factor (VIF) from PLS algorithm in SmartPLS. Using the PLS-SEM, the value of tolerance is 0.20 or lower and VIF 0.5 and higher to indicate the potential problem of collinearity [40]. As illustrated by Table 2 that VIF for every construct was less than the common cut-off threshold of 5.0. Thus, in this proposed study model, there is no collinearity issue.

Table 2. VIF values among model predictors.

\begin{tabular}{ll}
\hline Predictors & Dependent \\
\hline & $\mathrm{CM}$ \\
$\mathrm{C}$ & 3.29 \\
$\mathrm{I}$ & 2.923 \\
$\mathrm{R}$ & 1.737 \\
$\mathrm{~S}$ & 2.122 \\
\hline
\end{tabular}

Chin [58] PLS-SEM essential aim is to expand the dependent variable variance using the assessment of coefficient of determination (R2) of the endogenous constructs. It is preferred to achieve high $\mathrm{R}^{2}$ as indicating higher level of predictive accurateness. In the previous studies related to accounting, the values of $\mathrm{R} 2$ is assessed in the following basis: if it is $0.75,0.50$ and 0.25 for latent variables, it is regarded substantial, moderate, and weak, respectively [38]. Based on the $\mathrm{R}^{2}$ findings, the conceptual 
model shows a big portion of the variance in the endogenous construct as revealed in Table 3 as the values of $\mathrm{R}^{2}$ for competitive advantage and management control are 0.638 and 0.715 , respectively. This study is achieving satisfactory level of explanatory power for the proposed model.

Table 3. Results of R2.

\begin{tabular}{lll}
\hline & R Square & R Square Adjusted \\
\hline $\mathrm{CM}$ & 0.655 & 0.639 \\
\hline
\end{tabular}

Additionally, the Stone-Geisser's Q2 has examined by using the blindfolding procedure in order to evaluate the predictive relevance of the model. Referring to Table 4 which shows the positive Q2 values for all endogenous constructs and that suggest predictive relevance for the model [40].

Table 4. Results of Q2.

\begin{tabular}{llll}
\hline & SSO & SSE & $\mathbf{Q}^{2}(=\mathbf{1 - S S E} /$ SSO $)$ \\
\hline CM & $1,140.00$ & 695.623 & 0.39 \\
\hline
\end{tabular}

Hair et al. [39] mentioned that the evaluation of the relevance for every predictor construct (exogenous) on endogenous construct by the measurement of effect size $\mathrm{f}^{2}$.

It identifies the extent of the exogenous construct contribution to the target construct $\mathrm{R} 2$ value in the structural model. The $f 2$ values of $0.35,0.15$ and 0.02 signify as having large, medium and small degree of predictive relevance, respectively. Table 5 shows the findings of impact sizes of the structural model. The $f 2$ values of all important predictors were found to have a considerable impact on their endogenous variables in comparison to the unimportant predictors. The findings showed that integration effect on competitive advantage is the highest effect size with (0.15), followed by medium impact size of standardization on the competitive advantage (0.018), and the lowest impact size is routinization on competitive advantage (0.006).

Table 5. Results of $f$.

\begin{tabular}{ll}
\hline & CM \\
\hline C & 0 \\
$\mathrm{I}$ & 0.15 \\
$\mathrm{R}$ & 0.006 \\
$\mathrm{~S}$ & 0.018 \\
\hline
\end{tabular}

\section{Hypothesis Testing}

As SmartPLS 3.0 model and its path coefficient has similar explanation as regular beta weight in the analysis of regression. The range of the assessed path coefficient from -1 to +1 , if the path coefficient is close to +1 , it indicates that there is a strong positive association while -1 indicates there exists a strong negative association. Table 6 illustrates the path coefficient including the significance testing results, $t-$ statistic, standard error and the mediating effect.

The hypothesis testing dealt with only one path. The resulting hypothesis testing presents that the path was statistically significant at 0.001 levels 5 percent significance level is assumed as acceptable level in business literature
[39]. The path coefficient (refer to figure 1) was statistically significant positive direct effect of $\mathrm{I}, \mathrm{S}$ and $\mathrm{R}$ on $\mathrm{CM}$ with path coefficient of $\beta$ equal to $0.39(\mathrm{p}<0.000), 0.116(\mathrm{p}<$ $0.129)$ and $0.059(\mathrm{p}<0.337)$ respectively. Therefore, $\mathrm{H} 4, \mathrm{H} 2$ and $\mathrm{H} 1$ were supported. On the other side $\mathrm{C}$ was negatively effect on $\mathrm{CM}$ and it was insignificant $(\beta=-0.011, \mathrm{p}>$ 0.901), thus H3 was not supported.

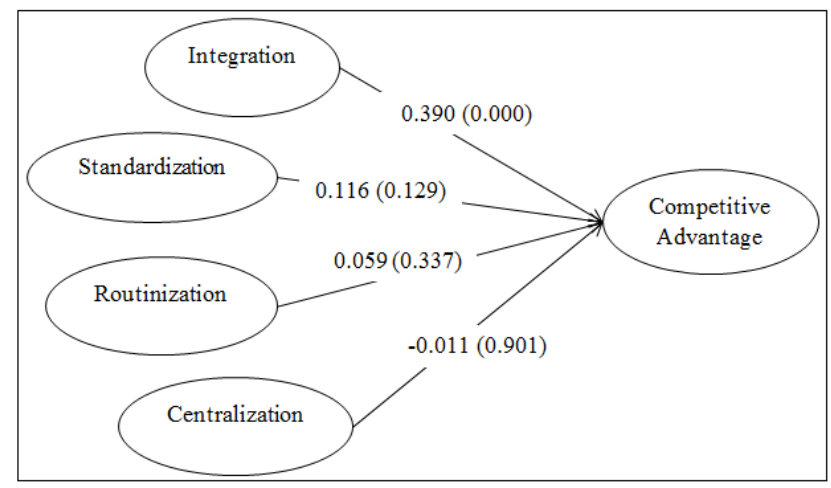

Figure 1. Results of Structural Modeling.

Table 6. Significance testing results of the structural model path coefficients.

\begin{tabular}{lllll}
\hline & Beta & P value & SE & T value \\
\hline C $->$ CM & -0.011 & 0.901 & 0.089 & 0.124 \\
I $>$ CM & 0.39 & 0 & 0.097 & 4.002 \\
R $->$ CM & 0.059 & 0.337 & 0.062 & 0.962 \\
S $->$ CM & 0.116 & 0.129 & 0.076 & 1.519 \\
\hline
\end{tabular}

\section{Discussion and Conclusion}

The obtained findings also reveal that centralization business process is positively associated with competitive advantage (H3). Thus, the study confirms the previous findings $[42,9,41]$ by providing evidence on the effect of ERP business process on competitive advantage while. Our findings show that business process attributes help are very significant to be assessed during ERP systems implementation to create competitive advantage.

Many limitations should be taken into account when making conclusions on the results of the current study. The size of sample is fairly small; and the ultimate model of the structural equation consists of responses from 114 over population of 3879 companies. Therefore, making generalizations of the ERPs role could not be possible without substantial caution. Although the data analyses of the present study have the essential conditions for proving the causal association, a bigger size of sample will produce robust findings.

Furthermore, it could be conceded that although the participants of the study are amongst the excellent executives of the companies, they might not be familiar with all the particulars of the required information when providing answers to some of the questionnaire items. Nevertheless, this bias (if any) in the current study constructs could affect the obtained results. Thus, this study opens the way for future studies by taking the opportunity to examine more closely the interaction between ERP and management control from different types of perspectives and compare the results. It 
would be interesting to find out whether the results of the current study could be applied in other parts of the worlds since the present study was conducted in Malaysia as developing county or trying to adopt same study from the perspective of service industry. Therefore, further research might result in refining several variables employed in this study and examine the competitive advantages of enterprises during ERP adoption with other factors likely to influence firms' performance. Finally, we confirm Snachez and
Spraakman [15] that ERP systems should be studied through its business process and attributes for better assessment.

\section{Acknowledgements}

The authors thank the Associate Prof. Dr. Amizawati Mohd Amir, Faculty of Economic and Management, University Kebangsaan Malaysia for her comments and suggestions for improving the paper.

\section{Appendix}

Table 7. The Outer Loading.

\begin{tabular}{|c|c|c|c|c|c|c|}
\hline & & $\begin{array}{l}\text { Outer Loading } \\
\text { (initial model) }\end{array}$ & \begin{tabular}{|l|}
$\begin{array}{l}\text { Outer Loading } \\
\text { (modified model) }\end{array}$ \\
\end{tabular} & Cronbach's Alpha & Composite Reliability & $\begin{array}{l}\text { Average Variance } \\
\text { Extracted (AVE) }\end{array}$ \\
\hline \multirow[t]{11}{*}{$\mathrm{CM}$} & CA1 & 0.762 & 0.759 & 0.942 & 0.950 & 0.659 \\
\hline & CA1 & 0.887 & 0.882 & & & \\
\hline & CA1 & 0.876 & deleted & & & \\
\hline & CA2 & 0.794 & 0.800 & & & \\
\hline & CA3 & 0.872 & 0.872 & & & \\
\hline & CA4 & 0.810 & 0.817 & & & \\
\hline & CA5 & 0.708 & 0.712 & & & \\
\hline & CA6 & 0.810 & 0.808 & & & \\
\hline & CA7 & 0.789 & 0.798 & & & \\
\hline & CA8 & 0.756 & 0.756 & & & \\
\hline & CA9 & 0.891 & 0.892 & & & \\
\hline \multirow[t]{9}{*}{$\mathrm{R}$} & R1 & 0.636 & 0.652 & 0.854 & 0.889 & 0.533 \\
\hline & $\mathrm{R} 2$ & 0.734 & 0.754 & & & \\
\hline & R3 & 0.715 & 0.745 & & & \\
\hline & R4 & 0.725 & 0.767 & & & \\
\hline & R5 & 0.755 & 0.751 & & & \\
\hline & R6 & 0.741 & 0.733 & & & \\
\hline & R7 & 0.712 & 0.703 & & & \\
\hline & $\mathrm{R} 8$ & 0.476 & deleted & & & \\
\hline & R9 & 0.348 & deleted & & & \\
\hline \multirow[t]{4}{*}{ S } & S1 & 0.811 & 0.809 & 0.860 & 0.905 & 0.705 \\
\hline & S2 & 0.861 & 0.864 & & & \\
\hline & S3 & 0.872 & 0.870 & & & \\
\hline & S4 & 0.812 & 0.813 & & & \\
\hline \multirow[t]{7}{*}{$\mathrm{C}$} & $\mathrm{C} 1$ & 0.849 & 0.850 & 0.932 & 0.945 & 0.712 \\
\hline & $\mathrm{C} 2$ & 0.850 & 0.850 & & & \\
\hline & $\mathrm{C} 3$ & 0.861 & 0.861 & & & \\
\hline & $\mathrm{C} 4$ & 0.867 & 0.867 & & & \\
\hline & $\mathrm{C} 5$ & 0.839 & 0.839 & & & \\
\hline & C6 & 0.810 & 0.810 & & & \\
\hline & $\mathrm{C} 7$ & 0.828 & 0.827 & & & \\
\hline \multirow[t]{17}{*}{ I } & I1 & 0.707 & 0.716 & 0.938 & 0.948 & 0.645 \\
\hline & I10 & 0.401 & deleted & & & \\
\hline & I11 & 0.803 & 0.801 & & & \\
\hline & $\mathrm{I} 12$ & 0.467 & deleted & & & \\
\hline & $\mathrm{I} 13$ & 0.612 & deleted & & & \\
\hline & I14 & 0.469 & deleted & & & \\
\hline & I1 5 & 0.569 & deleted & & & \\
\hline & I16 & 0.800 & 0.778 & & & \\
\hline & I17 & 0.509 & deleted & & & \\
\hline & I2 & 0.756 & 0.800 & & & \\
\hline & I3 & 0.403 & deleted & & & \\
\hline & I4 & 0.754 & 0.804 & & & \\
\hline & I5 & 0.790 & 0.833 & & & \\
\hline & I6 & 0.713 & 0.789 & & & \\
\hline & I7 & 0.803 & 0.844 & & & \\
\hline & I8 & 0.802 & 0.817 & & & \\
\hline & I9 & 0.807 & 0.840 & & & \\
\hline
\end{tabular}




\section{References}

[1] Cokins, G. (2013). Top 7 trends in management accounting. Strategic Finance, 95 (6), 21-30.

[2] Griffin, P. A., \& Wright, A. M. (2015). Commentaries on Big Data's importance for accounting and auditing. Accounting Horizons, 29 (2), 377-379.

[3] Boon-itt, S. (2009). The effect of internal and external supply chain integration on product quality and innovation: evidence from Thai automotive industry. International Journal of Integrated Supply Management, 5 (2), 97-112.

[4] Bustinza, O. F., Arias-Aranda, D., \& Gutierrez-Gutierrez, L. (2010). Outsourcing, competitive capabilities and performance: an empirical study in service firms. International Journal of Production Economics, 126 (2), 276-288.

[5] Day, G. S., \& Wensley, R. (1988). Assessing advantage: a framework for diagnosing competitive superiority. Journal of marketing, 52 (2), 1-20.

[6] Abushaiba, I. A., \& Zainuddin, Y. (2012). Performance measurement system design, competitive capability, and performance consequences-A conceptual like. International Journal of Business and Social Science, 3 (11).

[7] Warren Jr, J. D., Moffitt, K. C., \& Byrnes, P. (2015). How Big Data will change accounting. Accounting Horizons, 29 (2), 397-407.

[8] Redman, T. C. 2008. Data Driven: Profiting from Your Most Important Business Asset. Harvard Business Press.

[9] Kallunki, J.-P., Laitinen, E. K., \& Silvola, H. (2011). Impact of enterprise resource planning systems on management control systems and firm performance. International Journal of Accounting Information Systems, 12 (1), 20-39.

[10] Appelbaum, D., Kogan, A., Vasarhelyi, M., \& Yan, Z. (2017). Impact of business analytics and enterprise systems on managerial accounting. International Journal of Accounting Information Systems, 25, 29-44.

[11] Shores, B. (2005). Failure rates in global ITS projects and the leadership challenges. Journal of Global Information Management, 8 (3), 1-6.

[12] Liao, X., Li, Y., \& Lu, B. (2007). A model for selecting an ERP system based on linguistic information processing. Information Systems, 32 (7), 1005-1017.

[13] Scapens, R. W., \& Jazayeri, M. (2003). ERP systems and management accounting change: opportunities or impacts? A research note. European accounting review, 12 (1), 201-233.

[14] Magal, S. R., \& Word, J. (2009). Essentials of business processes and information systems: Wiley Publishing.

[15] Sánchez-Rodríguez, C., \& Spraakman, G. (2012). ERP systems and management accounting: A multiple case study. Qualitative Research in Accounting \& Management, 9 (4), 398-414.

[16] Hunton, J. E., Lippincott, B., \& Reck, J. L. (2003). Enterprise resource planning systems: comparing firm performance of adopters and nonadopters. International Journal of Accounting Information Systems, 4 (3), 165-184.
[17] Nicolaou, A. I. (2004). Firm performance effects in relation to the implementation and use of enterprise resource planning systems. Journal of information systems, 18 (2), 79-105.

[18] Nicolaou, A. I., \& Bhattacharya, S. (2006). Organizational performance effects of ERP systems usage: The impact of post-implementation changes. International Journal of Accounting Information Systems, 7 (1), 18-35.

[19] Wier, B., Hunton, J., \& HassabElnaby, H. R. (2007). RETRACTED: Enterprise resource planning systems and nonfinancial performance incentives: The joint impact on corporate performance: Elsevier.

[20] Dahlén, C. \& Elfsson, J. 1999. An Analysis of the Current and Future Erp Market. Industrial Economics and Management, The Royal Institut of Technology, Schweden.

[21] Kharabe, A., \& Lyytinen, K. J. (2012). Is implementing ERP like pouring concrete into a company? Impact of enterprise systems on organizational agility.

[22] Berente, N., Vandenbosch, B., \& Aubert, B. (2009). Information flows and business process integration. Business Process Management Journal, 15 (1), 119-141.

[23] Child, J., \& McGrath, R. G. (2001). Organizations unfettered: Organizational form in an information-intensive economy. Academy of management journal, 44 (6), 1135-1148.

[24] Aubert, B., Karyotakis, Y., Lees, J., Poireau, V., Prencipe, E., Prudent, X., Martinelli, M. (2009). Measurement of the $\gamma \gamma^{*} \rightarrow$ $\pi 0$ transition form factor. Physical Review D, 80 (5), 052002.

[25] Rom, A. \& Rohde, C. 2007. Management Accounting and Integrated Information Systems: A Literature Review. International Journal of Accounting Information Systems 8 (1): 40-68.

[26] Granlund, M., \& Malmi, T. (2002). Moderate impact of ERPS on management accounting: a lag or permanent outcome? Management accounting research, 13 (3), 299-321.

[27] Piccoli, G., \& Ives, B. (2005). IT-dependent strategic initiatives and sustained competitive advantage: a review and synthesis of the literature. MIS quarterly, 29 (4), 747-776.

[28] Molla, A., \& Bhalla, A. (2006). ERP and competitive advantage in developing countries: the case of an Asian company. The Electronic Journal of Information Systems in Developing Countries, 24 (1), 1-19.

[29] Alomari, I. A., Amir, A. M., Aziz, K. A., \& Auzair, S. M. (2018). Effect of enterprise resource planning systems and forms of management control on firm's competitive advantage. Asian Journal of Accounting and Governance, 9, 87-98.

[30] Acar, M. F., Tarim, M., Zaim, H., Zaim, S. \& Delen, D. 2017. Knowledge Management and Erp: Complementary or Contradictory? International Journal of Information Management 37 (6): 703-712.

[31] Muinde, C. M., Lewa, P., \& Kamau, J. N. (2016). The influence of top management support on knowledge sharing during the implementation of ERP systems in Kenya.

[32] Pishdad, A., \& Haider, A. (2013). ERP institutionalization: Exploring the influential factors. Journal of Enterprise Information Management, 26 (6), 642-660. 
[33] Jusoh, R., \& Parnell, J. A. (2008). Competitive strategy and performance measurement in the Malaysian context: An exploratory study. Management decision, 46 (1), 5-31.

[34] Pondeville, S., Swaen, V., \& De Rongé, Y. (2013). Environmental management control systems: The role of contextual and strategic factors. Management accounting research, 24 (4), 317-332.

[35] Kumar, K., Subramanian, R., \& Yauger, C. (1998). Examining the market orientation-performance relationship: a contextspecific study. Journal of management, 24 (2), 201-233.

[36] Chin, W. W. (1998). The partial least squares approach to structural equation modeling. Modern methods for business research, 295 (2), 295-336.

[37] Ylinen, M., \& Gullkvist, B. (2014). The effects of organic and mechanistic control in exploratory and exploitative innovations. Management accounting research, 25 (1), 93-112.

[38] F. Hair Jr, J., Sarstedt, M., Hopkins, L., \& G. Kuppelwieser, V. (2014). Partial least squares structural equation modeling (PLS-SEM) An emerging tool in business research. European Business Review, 26 (2), 106-121.

[39] Hair, J. F., Ringle, C. M., \& Sarstedt, M. (2013). Partial least squares structural equation modeling: Rigorous applications, better results and higher acceptance.

[40] Hair Jr, J. F., Hult, G. T. M., Ringle, C., \& Sarstedt, M. (2016). A primer on partial least squares structural equation modeling (PLS-SEM): Sage Publications.

[41] Ruivo, P., Oliveira, T., \& Neto, M. (2014). Examine ERP postimplementation stages of use and value: Empirical evidence from Portuguese SMEs. International Journal of Accounting Information Systems, 15 (2), 166-184.

[42] Chapman, C. S., \& Kihn, L.-A. (2009). Information system integration, enabling control and performance. Accounting, Organizations and Society, 34 (2), 151-169.

[43] Al-Mashari, M., Al-Mudimigh, A., \& Zairi, M. (2003). Enterprise resource planning: A taxonomy of critical factors. European journal of operational research, 146 (2), 352-364.

[44] Alomari, I., Amir, A. M., Aziz, K. A., \& Auzair, S. M. (2019). Enterprise resource planning system business process attributes: A research note. Int. J. Appl. Res. Stud, 5 (3), 111115 .

[45] Booth, P., Matolcsy, Z. \& Wieder, B. 2000. The Impacts of Enterprise Resource Planning Systems on Accounting Practice-the Australian Experience. Australian Accounting Review 10 (22): 4-18.

[46] Davenport, T. H. (1998). Putting the enterprise into the enterprise system. Harvard business review, 76 (4).

[47] Granlund, M. (2011). Extending AIS research to management accounting and control issues: A research note. International Journal of Accounting Information Systems, 12 (1), 3-19.

[48] Caglio, A. 2003. Enterprise Resource Planning Systems and Accountants: Towards Hybridization? European Accounting Review 12 (1): 123-153.

[49] Hage, J., \& Aiken, M. (1969). Routine technology, social structure, and organization goals. Administrative science quarterly, 366-376.
[50] Hall, E. T. (1963). A system for the notation of proxemic behavior. American anthropologist, 65 (5), 1003-1026.

[51] Lee, J., Siau, K., \& Hong, S. (2003). Enterprise Integration with ERP and EAI. Communications of the ACM, 46 (2), 5460 .

[52] Mirzaee, S., \& Ghaffari, A. (2018). Investigating the impact of information systems on knowledge sharing. Journal of Knowledge Management.

[53] Chenhall, R. H. (2003). Management control systems design within its organizational context: findings from contingencybased research and directions for the future. Accounting, Organizations and Society, 28 (2-3), 127-168.

[54] Hsu, C. L., \& Liao, Y. C. (2014). Exploring the linkages between perceived information accessibility and microblog stickiness: The moderating role of a sense of community. Information \& Management, 51 (7), 833-844.

[55] Wang, R. Y., \& Strong, D. M. (1996). Beyond accuracy: What data quality means to data consumers. Journal of management information systems, 12 (4), 5-33.

[56] Govindarajan, V. (1988). A contingency approach to strategy implementation at the business-unit level: integrating administrative mechanisms with strategy. Academy of management Journal, 31 (4), 828-853.

[57] Chenhall, R. H., \& Langfield-Smith, K. (1998). The relationship between strategic priorities, management techniques and management accounting: an empirical investigation using a systems approach. Accounting, Organizations and Society, 23 (3), 243-264.

[58] Chin, W. W. (2010). How to write up and report PLS analyses Handbook of partial least squares (pp. 655-690): Springer.

[59] Fornell, C., \& Larcker, D. F. (1981). Structural equation models with unobservable variables and measurement error: Algebra and statistics. Journal of Marketing Research, 382388 .

[60] Manrodt, K. B., \& Vitasek, K. (2004). Global process standardization: a case study. Journal of business logistics, 25 (1), 1-23.

[61] Wullenweber, K., \& Weitzel, T. (2007, January). An empirical exploration of how process standardization reduces outsourcing risks. In 2007 40th Annual Hawaii International Conference on System Sciences (HICSS'07) (pp. 240c-240c). IEEE.

[62] Ramakumar, A., \& Cooper, B. (2004). Process standardization proves profitable. Quality, 43(2), 42.

[63] Quattrone, P., \& Hopper, T. (2005). A 'time-space odyssey': management control systems in two multinational organisations. Accounting, organizations and society, 30 (7-8), 735-764.

[64] Chenhall, R. H., \& Morris, D. (1986). The impact of structure, environment, and interdependence on the perceived usefulness of management accounting systems. Accounting Review, 1635 .

[65] Chenhall, R. H. (2005). Integrative strategic performance measurement systems, strategic alignment of manufacturing, learning and strategic outcomes: an exploratory study. Accounting, organizations and society, 30 (5), 395-42. 